\title{
Which measuring site in ankylosing spondylitis is best to detect bone loss and what predicts the decline: results from a 5- year prospective study
}

Anna Deminger ${ }^{1 *}$, Eva Klingberg ${ }^{1}$, Mattias Lorentzon², Mats Geijer ${ }^{3,4}$, Jan Göthlin ${ }^{5}$, Martin Hedberg ${ }^{6}$, Eva Rehnberg ${ }^{7}$, Hans Carlsten ${ }^{1}$, Lennart T. Jacobsson ${ }^{1}$ and Helena Forsblad-d'Elia ${ }^{1,8}$

\begin{abstract}
Background: Studies have shown increased prevalence of osteoporosis and increased risk for vertebral fractures in patients with ankylosing spondylitis (AS). Measurements of bone mineral density (BMD) in the lumbar spine anterior-posterior (AP) projection may be difficult to interpret due to the ligamentous calcifications, and the lateral projection might be a better measuring site. Our objectives were to investigate BMD changes after 5 years at different measuring sites in patients with AS and to evaluate disease-related variables and medications as predictors for BMD changes.

Methods: In a longitudinal study, BMD in Swedish AS patients, $50 \pm 13$ years old, was measured with dual-energy $x$-ray absorptiometry (DXA) at the hip, the lumbar spine AP and lateral projections, and the total radius at baseline and after 5 years. Patients were assessed with questionnaires, blood samples, and spinal radiographs for grading of AS-related alterations in the spine with the modified Stoke Ankylosing Spondylitis Spinal Score (mSASSS) and assessment of vertebral fractures by the Genant score. Multiple linear regression analyses were used to investigate predictors for BMD changes.

Results: Of 204 patients included at baseline, 168 (82\%) were re-examined after 5 years (92 men and 76 women). BMD decreased significantly at the femoral neck and radius and increased significantly at the lumbar spine, both for AP and lateral projections. Mean C-reactive protein during follow-up predicted a decrease in the femoral neck BMD (change in $\%, \beta=-0.15, p=0.046)$. Use of bisphosphonates predicted an increase in BMD at all measuring sites $(p<$ 0.001 to 0.013 ), except for the total radius. Use of tumor necrosis factor inhibitors (TNFi) predicted an increase in AP spinal BMD $(\beta=3.15, p=0.012)$.

Conclusion: The current study (which has a long follow-up, many measuring sites, and is the first to longitudinally assess the lateral projection of the spine in AS patients) surprisingly showed that lateral projection spinal BMD increased. This study suggests that the best site to assess bone loss in AS patients is the femoral neck and that inflammation has an adverse effect, and the use of bisphosphonates and TNFi has a positive effect, on BMD in AS patients.
\end{abstract}

Keywords: Ankylosing spondylitis, Osteoporosis, Bone mineral density, Inflammation, Longitudinal study

\footnotetext{
* Correspondence: anna.deminger@vgregion.se

'Department of Rheumatology and Inflammation Research, Sahlgrenska

Academy at University of Gothenburg, Box 480, 40530 Gothenburg, Sweden

Full list of author information is available at the end of the article
} 


\section{Background}

Ankylosing spondylitis (AS) is a chronic, inflammatory disease mainly affecting the sacroiliac joints, the axial skeleton, and sometimes the peripheral joints. Two boneremodeling processes in AS include both new bone formation with development of syndesmophytes in the spine and bone loss with increased risk for osteoporosis and fractures. Studies have demonstrated increased prevalence of osteoporosis in patients with AS compared with sexand age-matched controls $[1,2]$. Low bone mineral density (BMD) of the lumbar spine and femoral neck has been observed in early AS and mild disease [2, 3]. AS patients also have an increased risk for vertebral fractures with a risk of instability and neurological injuries [4, 5].

Dual-energy $\mathrm{x}$-ray absorptiometry (DXA) is the routine method for assessing BMD [6]; however, measurements at the anterior-posterior (AP) projection of the spine in AS patients may be difficult to interpret due to ligamentous calcifications superimposed on the vertebrae or to sclerosis of the vertebral endplates $[1,7]$. The lateral projection of the spine supposedly more selectively measures the trabecular-rich vertebral body without contribution from cortical-rich posterior spinal elements [8]. There are some longitudinal studies on changes in BMD in AS [9-13]. To our knowledge, no reports on changes over time in the lateral projection of the spine have been published. In two studies on older men the lateral projection showed decreasing BMD over time whereas AP BMD increased $[14,15]$.

In some previous longitudinal studies on BMD in AS, a decrease in BMD was observed, especially in patients with active disease $[9-11,13]$. However, in order to give the patients optimal care more information is needed regarding predictors for osteoporosis and which measuring sites are best for diagnosis and monitoring of osteoporosis in this patient group. The aim of this study was to investigate how BMD changed over 5 years at five different measuring sites including the lateral projection of the spine and to evaluate disease-related variables and pharmacological treatments as predictors for the changes in BMD.

\section{Methods}

\section{Patients}

The patients were recruited at baseline in 2009 from rheumatology clinics at Sahlgrenska University Hospital in Gothenburg, Södra Älvsborg Hospital in Borås, and Alingsås Hospital, Sweden. The inclusion criterion was AS according to the modified New York criteria [16]. Exclusion criteria were psoriasis, inflammatory bowel disease, dementia, pregnancy, and difficulties in understanding the Swedish language. The 204 patients that completed the baseline protocol were invited to participate in the 5-year follow-up. Written informed consent was obtained and the study was approved by the regional ethics committee.

\section{Physical examination and questionnaires}

All physical examinations were repeated at follow-up, including the Bath Ankylosing Spondylitis Metrology Index (BASMI). Examinations were performed by one physician (EK) at baseline and one physician (AD) at follow-up. Patients answered a questionnaire concerning risk factors for osteoporosis, medical history, and medication. The Bath Ankylosing Spondylitis Disease Activity Index (BASDAI), the Bath Ankylosing Spondylitis Functional Index (BASFI), and the Bath Ankylosing Spondylitis Patient Global score (BAS-G) were obtained [17-20]. The Ankylosing Spondylitis Disease Activity Score based on C-reactive protein (ASDAS-CRP) was calculated [21, 22 ]. The amount of tobacco smoking for current and ever smokers was estimated by smoking pack years, calculated by multiplying the number of packs of cigarettes smoked per day by the number of years the person had ever smoked. Data on nonsteroidal anti-inflammatory drug (NSAID) consumption during follow-up was collected according to the Assessment of SpondyloArthritis International Society (ASAS) recommendations [23]. Use of glucocorticoids, converted into milligrams of prednisolone, and duration of treatment with tumor necrosis factor inhibitors (TNFi) and bisphosphonates were estimated from the medical records. Use of TNFi or bisphosphonate was calculated by dividing the number of months of exposure to either medication with follow-up time in months for all patients, resulting in a value $0-1$.

\section{Bone mineral density}

BMD measurements from the lumbar spine in the AP (vertebrae L1-L4) and lateral (L2-L4) projections, the left hip (femoral neck and total hip), and the non-dominant forearm (total radius) were obtained using the same DXA scanner (Hologic Discovery A, Hologic Inc., Bedford, MA, USA) at baseline and at follow-up. Precision as a percentage coefficient of variation $(\mathrm{CV})$ for repeated DXA measurements was $0.8 \%$ in the femoral neck, $0.6 \%$ in the total hip, $0.3 \%$ in the AP lumbar spine, $1.3 \%$ in the lateral lumbar spine, and $3.1 \%$ in the total radius. The World Health Organization (WHO) definitions for osteoporosis and osteopenia were used for patients $\geq 50$ years; osteoporosis, T-score $\leq-2.5 \mathrm{SD}$ (compared to the young normal mean) and osteopenia, T-score $<-1$ to $>-2.5 \mathrm{SD}$ [6]. For patients $<50$ years a Z-score $\leq-2.0 \mathrm{SD}$ (compared to ageand sex-matched mean) was considered to be below the expected range for age [24] and a Z-score $<-1$ SD to be subnormal. T- and Z-score reference values were provided by the DXA scanner manufacturer. The Hologic reference database consists of more than 45,000 observations from the USA and the current study used reference material from non-Hispanic white adults from the USA. Volumetric $\mathrm{BMD}$ (vBMD), a three-dimensional mode to assess bone mineral content per volume, was estimated by 
combining AP with lateral DXA scanning of the lumbar spine. Reference values were not available for lateral lumbar spine DXA for men or for vBMD for either sex.

\section{Radiography}

Lateral radiographs of the spine were acquired at baseline and at follow-up. Osteoproliferative changes related to AS were assessed in the cervical and lumbar spine by the modified Stoke Ankylosing Spondylitis Spine Score (mSASSS). The score ranges from 0 to 72 [25]. The radiographs were also assessed for vertebral fractures (VFs) by the semiquantitative method Genant score. Vertebrae T4-L4 were assessed for reductions in height and graded $0=$ normal, $1=$ mild, $2=$ moderate, and $3=$ severe VF based on how large was the height reduction [26]. A progress in Genant score was defined as development of a new fracture in a previously normal vertebra or a worsening of at least 1 point in Genant score. All radiographs at baseline and follow-up were assessed by the same musculoskeletal radiologist (MG).

\section{Laboratory tests}

Blood samples were analyzed using standard laboratory techniques. The mean level of erythrocyte sedimentation rate (ESR) and C-reactive protein (CRP) for the last 5 years before follow-up were obtained from the medical records. Mean ESR/CRP was calculated using the first recorded test for each year unless the patient had an infection; in that case the ESR/CRP was replaced by the subsequent test.

\section{Statistics}

Statistical analyses were performed using IBM SPSS Statistics 22 (IBM Corp., Armonk, NY, USA). Descriptive statistics are presented as mean and standard deviation (SD) or standard error of the mean (SEM). To compare different groups the $t$ test or the Mann-Whitney $U$ test were used for continuous variables, and the Chi-square test used for categorical variables. For repeated measurements, a paired $t$ test or the Wilcoxon rank sign test were used for continuous variables, and McNemar's test for categorical variables. A one-sided $t$ test was used to compare the Z-score in patients to the test value 0 . The $\Delta$ values were calculated by subtracting the baseline value from the follow-up value. Standard multiple linear regression analyses were run with $\triangle \mathrm{BMD}$ at the different measuring sites as a dependent variable. Predictor variables used in the models were demographic variables known to affect BMD (age, gender, smoking pack years, and $\Delta$ body weight) together with disease-related variables (mSASSS at baseline and one of the following: baseline BASDAI or ASDAS-CRP, mean CRP or mean ESR during follow-up, or $\triangle \mathrm{CRP}$ or $\triangle \mathrm{ESR}$ ) as well as medications (NSAID, bisphosphonates, and TNFi) that were hypothesized to influence changes in BMD. Mean $\mathrm{CRP} / \triangle \mathrm{CRP}$ or mean ESR/ $\triangle \mathrm{ESR}$ was chosen depending on which gave the best model. Baseline BMD at the same measuring site and time between DXA measurements were also included in the models. Sex and menopause correlated too closely with each other to be included in the same model, and thus were used in separate models. There was no multicollinearity and residuals were analyzed. All tests were two-tailed and $p \leq 0.05$ was considered statistically significant. Bonferroni correction was used for multiple comparisons.

\section{Results}

\section{Patients}

Of the 204 patients from baseline, 168 (82\%) patients (55\% men) completed all examinations at the 5-year follow-up (Fig. 1). Two patients had to be excluded from the lateral examinations due to insufficient quality, but the rest of the patients had three vertebrae legible in this projection.

Baseline and follow-up characteristics as well as medications are reported in Table 1 . The mean age did not differ between men and women $(49 \pm 13$ years vs $51 \pm 13$ years, $p=0.50)$, and neither did the duration of symptoms $(24 \pm 13$ years for both sexes, $p=0.73)$.

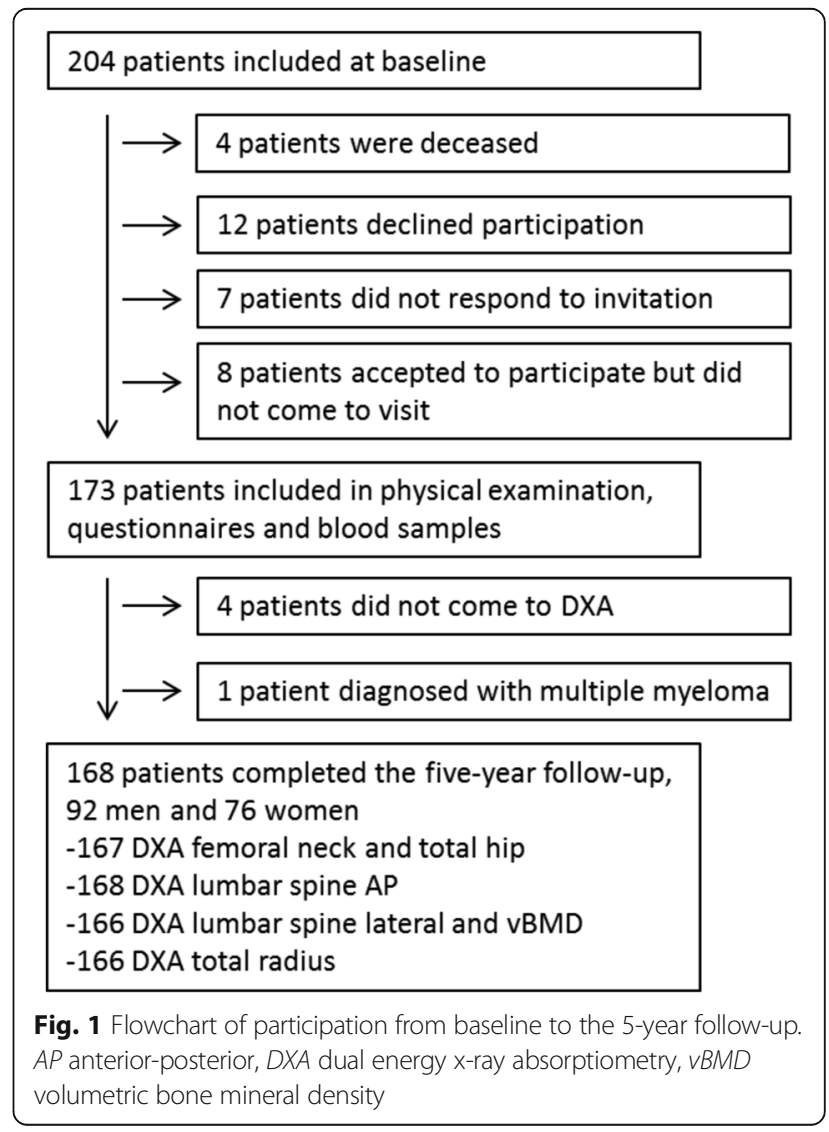


Table 1 Characteristics of 168 patients with ankylosing spondylitis at baseline and at 5-year follow-up

\begin{tabular}{|c|c|c|c|}
\hline & Baseline & 5-year follow-up & $p$ value \\
\hline \multicolumn{4}{|l|}{ Demographic variables } \\
\hline Sex, male/female & $92(55) / 76(45)$ & & \\
\hline Age, years & $50 \pm 13$ & $55 \pm 13$ & $<0.001$ \\
\hline Postmenopausal women & $38 / 76(50)$ & $47 / 76(62)$ & 0.004 \\
\hline Current smokers & $17(10)$ & $13(8)$ & 0.4 \\
\hline Pack years & $5.5 \pm 10.0$ & $7.0 \pm 11.3$ & $<0.001$ \\
\hline Weight, kg & $77 \pm 16$ & $79 \pm 17$ & $<0.001$ \\
\hline Height, cm & $172 \pm 10$ & $171 \pm 10$ & $<0.001$ \\
\hline Time between DXA measurements, months & & $60.0 \pm 2.0$ & \\
\hline \multicolumn{4}{|l|}{ Disease-related variables } \\
\hline Duration of symptoms, years & $24 \pm 13$ & $29 \pm 13$ & $<0.001$ \\
\hline History of anterior uveitis & $87(52)$ & $97(58)$ & 0.002 \\
\hline History of peripheral arthritis & $98(58)$ & $106(63)$ & 0.008 \\
\hline History of coxitis & $13(8)$ & $17(10)$ & 0.1 \\
\hline BASMI, score & $3.1 \pm 1.6$ & $3.5 \pm 1.6$ & $<0.001$ \\
\hline BASFI, score & $2.5 \pm 2.0$ & $2.7 \pm 2.1$ & 0.1 \\
\hline BASDAI, score & $3.4 \pm 2.1$ & $3.5 \pm 2.0$ & 0.4 \\
\hline ASDAS-CRP, score & $2.1 \pm 0.9$ & $2.1 \pm 0.9$ & 0.8 \\
\hline$C R P, m g / L$ & $5.5 \pm 8.4$ & $4.7 \pm 5.2$ & 0.2 \\
\hline Mean CRP last 5 years, mg/L & & $5.8 \pm 5.9$ & \\
\hline $\mathrm{ESR}, \mathrm{mm} / \mathrm{h}$ & $14.2 \pm 11.2$ & $11.2 \pm 10.4$ & 0.001 \\
\hline Mean ESR last 5 years, mm/h & & $12.4 \pm 8.7$ & \\
\hline mSASSS, score & $15.0 \pm 20.0$ & $16.6 \pm 20.9$ & $<0.001$ \\
\hline HLA-B27 positive & $145(86)$ & & \\
\hline \multicolumn{4}{|l|}{ Medications } \\
\hline Patients on NSAIDs at visit & $131(78)$ & $112(67)$ & 0.004 \\
\hline Exposure to NSAIDs during follow-up & & $145(86)$ & \\
\hline NSAID-index during follow-up, 0-100 & & $34.5 \pm 37.1$ & \\
\hline Patients on TNFi at visit & $33(20)$ & $38(23)$ & 0.3 \\
\hline Exposure to TNFi during follow-up & & $49(29)$ & \\
\hline Use of TNFi during follow-up, $0-1$ & & $0.2 \pm 0.4$ & \\
\hline Patients on GC at visit & $5(3)$ & $3(2)$ & 0.6 \\
\hline Exposure to GC during follow-up & & $30(18)$ & \\
\hline Patients on bisphosphonate at visit & $7(4)$ & $8(5)$ & 1.00 \\
\hline Exposure to bisphosphonate during follow-up & & $30(18)$ & \\
\hline Use of bisphosphonate during follow-up, 0-1 & & $0.1 \pm 0.3$ & \\
\hline Patients on MHT at visit & $6 / 76(8)$ & $4 / 76(5)$ & 0.7 \\
\hline Exposure to MHT during follow-up & & $9 / 76(12)$ & \\
\hline
\end{tabular}

Values are mean \pm SD or numbers of patients (\%)

ASDAS-CRP Ankylosing Spondylitis Disease Activity Score based on C-reactive protein, BASDAI Bath Ankylosing Spondylitis Disease Activity Index, BASFI Bath Ankylosing Spondylitis Functional Index, BASMI Bath Ankylosing Spondylitis Metrology Index, CRP C-reactive protein, DXA dual-energy x-ray absorptiometry, ESR erythrocyte sedimentation rate, GC glucocorticoid, MHT menopausal hormone therapy, mSASSS modified Stoke Ankylosing Spondylitis Spine Score, NSAID nonsteroidal anti-inflammatory drug, TNFi tumor necrosis factor inhibitor 


\section{Five-year BMD changes}

Over 5 years, significant changes in BMD occurred at all five different measuring sites for the total group. For both sexes, BMD decreased at the femoral neck and the total radius. At the total hip and for the AP and lateral projections (including vBMD) of the spine BMD increased, changes that were statistically significant only in men (Fig. 2). The Pearson correlation coefficient for $\mathrm{BMD}$ at $\mathrm{AP}$ and lateral spine was 0.68 at both baseline and follow-up and 0.84 for $\triangle \mathrm{BMD}(p<0.001)$.

\section{Prevalence of low BMD}

At baseline, 23\% of the patients had osteoporosis according to the WHO definition or BMD below the expected range for age at any measuring site compared to $27 \%$ at follow-up, while $35 \%$ had osteopenia or Z-score $<-1$ SD at baseline compared to $32 \%$ at follow-up. These prevalences had not changed significantly $(p=0.34$ for osteopenia) from baseline. Women had higher prevalence of osteoporosis/BMD below the expected range for age than men, both at baseline and follow-up (Table 2).

The total AS group did not differ significantly from the reference group at any measuring site for BMD at baseline. At the 5-year follow-up, the total group had significantly higher BMD than the reference group at the total hip and AP lumbar spine $(p=0.002$ and 0.001 , respectively) (Table 3).

\section{Predictors for changes in BMD}

The results from the multiple linear regression analyses with $\triangle B M D$ at the various measuring sites as a dependent variable are shown in Table 4. Higher mean
CRP during follow-up was associated with decreasing femoral neck BMD. Decreases in ESR were associated with increases in BMD at the total hip, and the AP, lateral, and vBMD lumbar spine (similar results were seen for $\triangle \mathrm{CRP}$ but resulted in lower $R^{2}$ values). No associations with $\triangle \mathrm{BMD}$ were observed for mean ESR, baseline BASDAI, or ASDAS-CRP. Low mSASSS was a predictor for BMD decrease in the femoral neck. On exchanging mSASSS to lumbar mSASSS as a covariate, no association with $\triangle \mathrm{BMD}$ was seen. Increased weight was associated with increased BMD at all measuring sites except the femoral neck and radius.

Male sex predicted an increase in total hip BMD. If sex was changed to menopause as a covariate, significance was only seen for menopause at the total radius $(\beta=-2.04, p=0.036)$. Menopause during follow-up was not a significant covariate. A multivariate regression model including synovitis and uveitis was performed; they were not significant covariates and did not improve prediction of the model.

Exposure to medication was related to $\triangle \mathrm{BMD}$; use of bisphosphonate predicted an increase in BMD at all measuring sites except the radius. Use of TNFi predicted an increase in AP lumbar spine BMD (Table 4).

To further study if osteoproliferation had an impact on $\triangle \mathrm{BMD}$, patients $<50$ years with syndesmophytes at baseline were compared with patients without syndesmophytes. The osteoproliferative group had higher $\triangle \mathrm{BMD}$ in the AP spine and total hip (Table 5). However, in regression analyses, no association with mSASSS and $\triangle B M D$ was seen. In the group with syndesmophytes $52 \%$ of the patients had exposure of TNFi during follow-

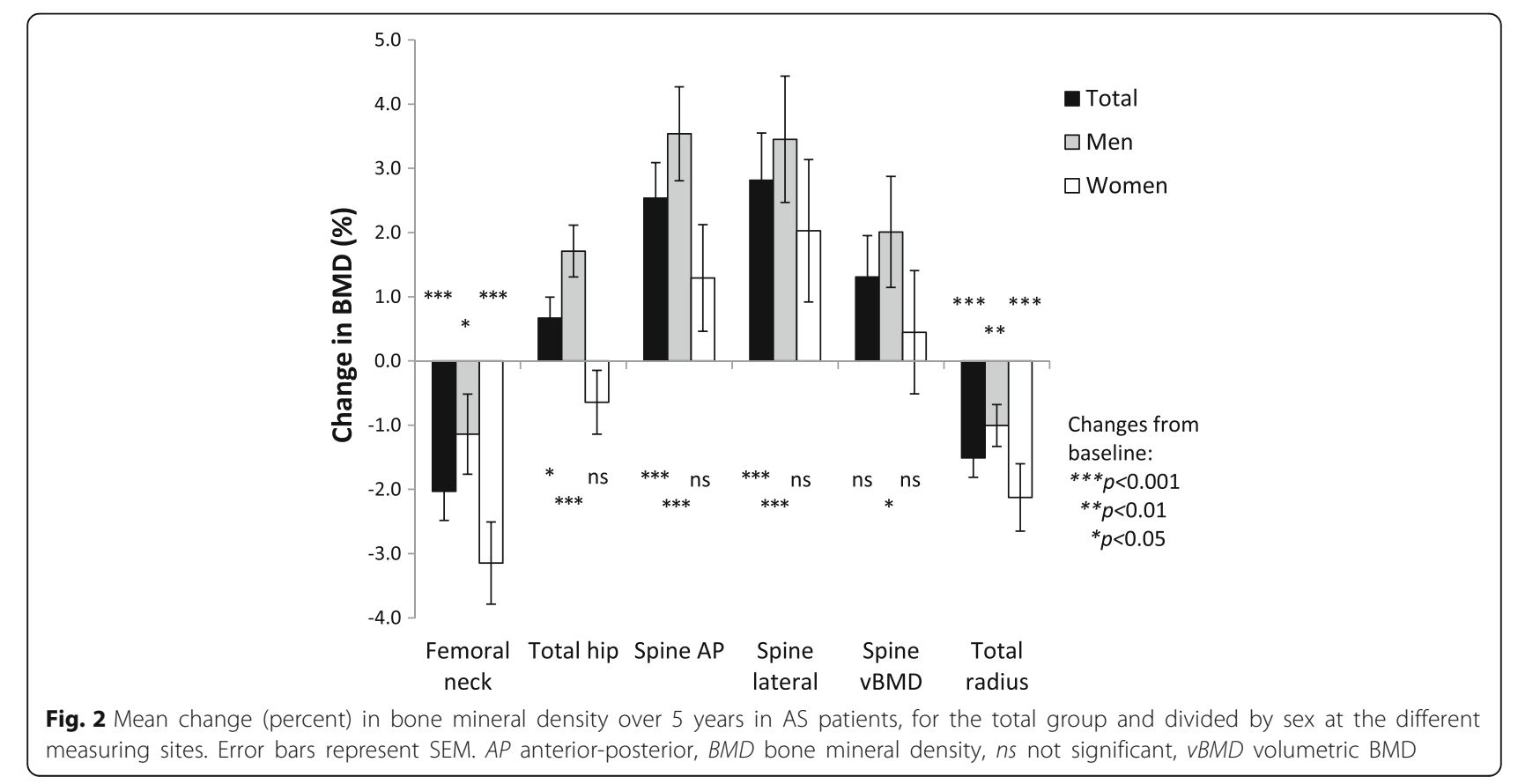


Table 2 Frequency of osteoporosis at baseline and at the 5-year follow-up

\begin{tabular}{|c|c|c|c|c|}
\hline \multirow[t]{2}{*}{ Measuring site } & \multirow[t]{2}{*}{ Group } & \multicolumn{2}{|c|}{ Patients with osteoporosis/BMD below expected range for age } & \multirow[t]{2}{*}{$p$ value } \\
\hline & & Baseline & 5-year follow-up & \\
\hline \multirow[t]{3}{*}{ Any measuring site } & Total & $39(23)$ & $45(27)$ & 0.24 \\
\hline & Men & $12(13)^{* *}$ & $16(17)^{* *}$ & 0.29 \\
\hline & Women & $27(36)$ & $29(38)$ & 0.75 \\
\hline \multirow[t]{3}{*}{ Femoral neck } & Total & $10(6)$ & $12(7)$ & 0.72 \\
\hline & Men & $6(7)$ & $7(8)$ & 1.00 \\
\hline & Women & $4(5)$ & $5(7)$ & 1.00 \\
\hline \multirow[t]{3}{*}{ Total hip } & Total & $1(1)$ & $1(1)$ & 1.00 \\
\hline & Men & $1(1)$ & $1(1)$ & 1.00 \\
\hline & Women & $0(0)$ & $0(0)$ & - \\
\hline \multirow[t]{3}{*}{ Spine AP } & Total & $16(10)$ & $12(7)$ & 0.39 \\
\hline & Men & $4(4)^{*}$ & $2(2)^{* *}$ & 0.69 \\
\hline & Women & $12(16)$ & $10(13)$ & 0.69 \\
\hline \multirow[t]{3}{*}{ Spine lateral } & Total & NA & NA & NA \\
\hline & Men & NA & NA & NA \\
\hline & Women & $20(26)$ & $18(24)$ & 0.63 \\
\hline \multirow[t]{3}{*}{ Total radius } & Total & $13(8)$ & $20(12)$ & 0.04 \\
\hline & Men & 7 (8) & $11(12)$ & 0.13 \\
\hline & Women & $6(8)$ & $9(12)$ & 0.38 \\
\hline
\end{tabular}

Values are numbers (\%)

${ }^{*} p<0.05,{ }^{* *} p<0.01$, versus women

Significant $p$ values are shown in bold typeface

$A P$ anterior-posterior, $B M D$ bone mineral density, $N A$ not available

up compared to $26 \%$ in those without syndesmophytes $(p=0.036)$. The exposure of bisphosphonates also differed between the groups; $19 \%$ of patients with syndesmophytes vs $3.3 \%$ without syndesmophytes $(p=0.026)$.

\section{Subgroup analyses of different medications}

To further study the impact of treatment on $\triangle B M D$, subgroup analyses for different treatment groups were performed in the total group of patients. Patients exposed neither to bisphosphonates nor TNFi during follow-up were compared with patients exposed to bisphosphonates, to patients exposed to TNFi, and to patients exposed to both bisphosphonates and TNFi (Fig. 3).

BMD decreased significantly at the femoral neck and the total radius in patients without bisphosphonates but was stable in patients exposed to bisphosphonates. Compared to patients exposed to bisphosphonates, patients without exposure to bisphosphonates and TNFi had significantly decreased femoral neck BMD (difference in $\triangle \mathrm{BMD} 4 \%, p=0.03$ ) (Fig. 3).

All patients with exposure to bisphosphonates and/or TNFi had significantly increased AP lumbar spine and total hip BMD compared with non-exposed patients ( $p$ $<0.001$ to 0.048 ) except at the total hip for combination therapy $(p=0.075)$. There was no significant difference for $\triangle \mathrm{BMD}$ at the lateral spine between non-exposed patients and patients exposed to bisphosphonates and/or TNFi (Fig. 3).

The group without exposure to medication was further studied with the same regression models (except treatments) as described previously. Higher mean ESR during follow-up was associated with a decrease in BMD at all sites except for the AP spine and total radius (Table 6).

\section{Vertebral fractures}

Of $17(10 \%)$ patients with VF at baseline, only three (1.8\%) had progressed in Genant score. Two patients without fractures at baseline had developed vertebral fractures at follow-up, both in the lumbar spine. One of them developed a grade $1 \mathrm{VF}$ and the other patient developed two grade 2 fractures. The third patient already had four VF at baseline located in the thoracic spine and developed one new VF grade 2 in the thoracic spine and worsened from grade 2 to grade 3 in one existing VF. Excluding patients with VF did not alter the $\triangle \mathrm{BMD}$ at the different measuring sites for the group. There were too few patients with new VF to assess VF predictors.

\section{Discussion}

The current study has shown that BMD in AS patients after 5 years decreased at the femoral neck and total radius and increased at the total hip and the lumbar spine, 
Table 3 Bone mineral density, T-score and Z-score at baseline and the 5-year follow-up

\begin{tabular}{|c|c|c|c|c|c|c|c|}
\hline Site & Group & $\begin{array}{l}\text { Baseline BMD, } \\
\mathrm{g} / \mathrm{cm}^{2}\end{array}$ & $\begin{array}{l}\text { Follow-up BMD, } \\
\mathrm{g} / \mathrm{cm}^{2}\end{array}$ & $\begin{array}{l}\text { Baseline } \\
\text { T-score, SD }\end{array}$ & $\begin{array}{l}\text { Follow-up } \\
\text { T-score, SD }\end{array}$ & $\begin{array}{l}\text { Baseline } \\
\text { Z-score, SD }\end{array}$ & $\begin{array}{l}\text { Follow-up } \\
\text { Z-score, SD }\end{array}$ \\
\hline \multirow[t]{3}{*}{ Femoral neck } & Total & $0.78 \pm 0.13$ & $0.77 \pm 0.13^{* * *}$ & $-0.9 \pm 1.0$ & $-1.0 \pm 1.0^{* * *}$ & $-0.1 \pm 1.0$ & $-0.1 \pm 0.9$ \\
\hline & Men & $0.80 \pm 0.13$ & $0.79 \pm 0.12^{*}$ & $-0.9 \pm 0.9$ & $-1.0 \pm 0.9$ & $-0.2 \pm 0.9$ & $-0.2 \pm 0.9$ \\
\hline & Women & $0.76 \pm 0.13$ & $0.73 \pm 0.13^{* * *}$ & $-0.8 \pm 1.1$ & $-1.0 \pm 1.1^{* * *}$ & $0.0 \pm 1.0$ & $0.0 \pm 1.0$ \\
\hline \multirow[t]{3}{*}{ Total hip } & Total & $0.94 \pm 0.14$ & $0.94 \pm 0.14^{*}$ & $-0.4 \pm 0.9$ & $-0.4 \pm 1.0$ & $0.0 \pm 0.9$ & $0.2 \pm 0.9^{* * *}$ \\
\hline & Men & $0.98 \pm 0.13$ & $0.99 \pm 0.13^{* * *}$ & $-0.4 \pm 0.9$ & $-0.3 \pm 0.9^{* * *}$ & $-0.1 \pm 0.9$ & $0.2 \pm 0.9^{* * *}$ \\
\hline & Women & $0.89 \pm 0.13$ & $0.88 \pm 0.13$ & $-0.4 \pm 1.0$ & $-0.5 \pm 1.1$ & $0.1 \pm 0.9$ & $0.3 \pm 1.0^{* * *}$ \\
\hline \multirow[t]{3}{*}{ Lumbar spine AP } & Total & $1.03 \pm 0.18$ & $1.05 \pm 0.19^{* * *}$ & $-0.4 \pm 1.5$ & $-0.2 \pm 1.6^{* * *}$ & $0.2 \pm 1.5$ & $0.6 \pm 1.6^{* * *}$ \\
\hline & Men & $1.08 \pm 0.17$ & $1.11 \pm 0.18^{* * *}$ & $-0.1 \pm 1.6$ & $0.2 \pm 1.6^{* * *}$ & $0.2 \pm 1.7$ & $0.7 \pm 1.7^{* * *}$ \\
\hline & Women & $0.96 \pm 0.16$ & $0.97 \pm 0.17$ & $-0.8 \pm 1.4$ & $-0.7 \pm 1.5$ & $0.1 \pm 1.4$ & $0.5 \pm 1.5^{* * *}$ \\
\hline \multirow[t]{3}{*}{ Lumbar spine lateral } & Total & $0.72 \pm 0.13$ & $0.74 \pm 0.14^{* * *}$ & NA & NA & NA & NA \\
\hline & Men & $0.76 \pm 0.12$ & $0.79 \pm 0.14^{* * *}$ & NA & NA & NA & NA \\
\hline & Women & $0.68 \pm 0.13$ & $0.69 \pm 0.13$ & $-1.7 \pm 1.5$ & $-1.6 \pm 1.6$ & $-0.1 \pm 1.4$ & $0.4 \pm 1.5^{* * *}$ \\
\hline \multirow[t]{3}{*}{ Lumbar spine $v B M D$} & Total & $0.19 \pm 0.03$ & $0.19 \pm 0.03$ & NA & NA & NA & NA \\
\hline & Men & $0.19 \pm 0.03$ & $0.19 \pm 0.03^{*}$ & NA & NA & NA & NA \\
\hline & Women & $0.19 \pm 0.04$ & $0.20 \pm 0.04$ & NA & NA & NA & NA \\
\hline \multirow[t]{3}{*}{ Total radius } & Total & $0.60 \pm 0.08$ & $0.59 \pm 0.08^{* * *}$ & $-0.7 \pm 1.1$ & $-0.8 \pm 1.2^{* * *}$ & $-0.0 \pm 1.0$ & $0.0 \pm 1.1$ \\
\hline & Men & $0.65 \pm 0.06$ & $0.64 \pm 0.06^{* *}$ & $-0.7 \pm 1.1$ & $-0.8 \pm 1.1^{* *}$ & $-0.2 \pm 1.0$ & $-0.2 \pm 1.1$ \\
\hline & Women & $0.54 \pm 0.06$ & $0.53 \pm 0.07^{* * *}$ & $-0.6 \pm 1.1$ & $-0.8 \pm 1.3^{* * *}$ & $0.2 \pm 0.9$ & $0.3 \pm 1.0$ \\
\hline
\end{tabular}

Values are mean \pm SD

${ }^{*} p<0.05,{ }^{* *} p<0.01,{ }^{* * *} p<0.001$, versus baseline

$A P$ anterior-posterior, $B M D$ bone mineral density, NA not available, $S D$ standard deviation, $v B M D$ volumetric BMD

both for AP and lateral projections. Inflammation as measured by CRP or ESR was associated with a decrease in BMD. Previous longitudinal BMD studies in AS patients have mainly assessed BMD at the hip region and the AP projection of the lumbar spine [9-11, 27]. One study of early inflammatory back pain included the hand [13] and another included the forearm [12]. One previous study, in line with our findings, reported reduction of femoral neck BMD and a more pronounced decrease in BMD in patients with high ESR during follow-up [11]. Two studies only have reported a significant reduction of femoral neck BMD in patients with active disease during follow-up [9, 13]. Wang et al. reported BMD increases in both the femoral neck and forearm; however, in regression analyses high ESR at baseline was associated with decreased BMD in the femur [12]. Haugeberg et al. found no change in $\triangle B M D$ of the hands [13]. The small decrease in BMD at the total radius in the current study should be interpreted with caution considering the relatively large $\mathrm{CV}$ at this site. The only predictors for a decrease in BMD at the total radius in the current study were age and menopause.

In the current study, in contrast to decreasing femoral neck BMD, total hip BMD increased, especially for younger patients with syndesmophytes who also had a greater exposure to TNFi and bisphosphonates compared to those without syndesmophytes. The total hip has been studied less longitudinally than the femoral neck in AS patients. Previous studies have shown decreased BMD $[10,13]$. Our patients also had higher total hip BMD at follow-up compared with the reference group. Increased BMD was seen in patients exposed to bisphosphonates and/or TNFi. The part of the total hip that showed increased BMD was the trochanter. Trochanteric BMD has been shown to increase more with bisphosphonates than femoral neck BMD [28]. In the current study, the hip was not radiographed, and thus arthritic changes cannot be accounted for. The results in the current study suggest that the femoral neck is the best site for assessing bone loss in AS patients.

In the spine, $\mathrm{BMD}$ in both the $\mathrm{AP}$ and lateral projections increased during follow-up. The increase in the AP projection may be due to the osteoproliferation that may occur in the spine in AS patients $[1,7]$. Use of the lateral projection of the lumbar spine has been suggested to exclude much of the osteoproliferative changes seen in AS. Two cross-sectional studies have shown lower lumbar BMD in the lateral projection but not in the AP projection when comparing AS patients with healthy controls [29, 30]. A report on baseline data in the current study showed that AP lumbar spine BMD was significantly higher than lateral spine BMD [31]. Our current study is the first to evaluate the lateral projection longitudinally in AS patients and it was unexpected to find increasing BMD. Since we 
Table 4 Multiple linear regression analyses with $\triangle B M D$ (change in \%) as a dependent variable

\begin{tabular}{|c|c|c|c|c|c|c|c|c|c|c|c|c|}
\hline \multirow{3}{*}{ Constant } & \multirow{2}{*}{\multicolumn{2}{|c|}{$\begin{array}{l}\text { Femoral neck } \\
20.4\end{array}$}} & \multirow{2}{*}{\multicolumn{2}{|c|}{$\begin{array}{l}\text { Total hip } \\
1.5\end{array}$}} & \multirow{2}{*}{\multicolumn{2}{|c|}{$\begin{array}{l}\text { Spine AP } \\
-13.4\end{array}$}} & \multirow{2}{*}{\multicolumn{2}{|c|}{$\begin{array}{l}\text { Spine lateral } \\
-47.3\end{array}$}} & \multirow{2}{*}{\multicolumn{2}{|c|}{$\begin{array}{l}\text { Spine vBMD } \\
-40.5\end{array}$}} & \multirow{2}{*}{\multicolumn{2}{|c|}{$\begin{array}{l}\text { Total radius } \\
10.4\end{array}$}} \\
\hline & & & & & & & & & & & & \\
\hline & $\beta$ & $p$ & $\beta$ & $p$ & $\beta$ & $p$ & $\beta$ & $p$ & $\beta$ & $p$ & $\beta$ & $p$ \\
\hline \multicolumn{13}{|l|}{ Baseline } \\
\hline BMD at same site, $\mathrm{g} / \mathrm{cm}^{2}$ & -8.24 & 0.036 & 0.98 & 0.67 & 0.80 & 0.80 & 0.81 & 0.89 & -16.3 & 0.42 & 2.89 & 0.60 \\
\hline Age, years & -0.12 & 0.006 & -0.05 & 0.063 & -0.04 & 0.31 & -0.04 & 0.50 & -0.07 & 0.22 & -0.11 & $<0.001$ \\
\hline Sex & -1.61 & 0.11 & -1.68 & 0.007 & -2.06 & 0.051 & -1.70 & 0.27 & -1.47 & 0.25 & -0.47 & 0.58 \\
\hline Pack years & 0.13 & 0.004 & 0.08 & 0.003 & 0.09 & 0.054 & 0.12 & 0.086 & 0.09 & 0.12 & -0.04 & 0.16 \\
\hline mSASSS, score & 0.06 & 0.041 & 0.005 & 0.76 & -0.03 & 0.27 & -0.08 & 0.052 & -0.06 & 0.10 & 0.02 & 0.26 \\
\hline \multicolumn{13}{|l|}{ During follow-up } \\
\hline Time between DXA, months & -0.19 & 0.41 & -0.02 & 0.86 & 0.24 & 0.31 & 0.81 & 0.016 & 0.77 & 0.009 & -0.14 & 0.36 \\
\hline$\Delta$ weight, kg & 0.03 & 0.72 & 0.24 & $<0.001$ & 0.37 & $<0.001$ & 0.49 & $<0.001$ & 0.51 & $<0.001$ & 0.08 & 0.18 \\
\hline NSAID-index, 0-100 & 0.02 & 0.064 & 0.01 & 0.097 & 0.01 & 0.42 & 0.01 & 0.56 & 0.00 & 0.89 & 0.01 & 0.26 \\
\hline Use of TNFi, 0-1 & -1.53 & 0.11 & 1.23 & 0.086 & 3.15 & 0.012 & 2.17 & 0.22 & 1.06 & 0.49 & -0.65 & 0.41 \\
\hline Use of bisphosphonate, 0-1 & 4.64 & 0.013 & 5.61 & $<0.001$ & 13.7 & $<0.001$ & 15.5 & $<0.001$ & 11.6 & $<0.001$ & 0.83 & 0.48 \\
\hline Mean CRP last 5 years, mg/L & -0.15 & 0.046 & NA & & NA & & NA & & NA & & -0.09 & 0.072 \\
\hline$\Delta \mathrm{ESR}, \mathrm{mm} / \mathrm{h}$ & NA & & -0.10 & $<0.001$ & -0.12 & 0.004 & -0.16 & 0.007 & -0.13 & 0.012 & NA & \\
\hline$R^{2}$ & 0.22 & & 0.44 & & 0.41 & & 0.33 & & 0.34 & & 0.20 & \\
\hline
\end{tabular}

$\beta$ are unstandardized coefficients

Coding for sex: $\operatorname{man}=0$, woman $=1$

Significant $\beta$ and $p$ values are shown in bold typeface

$A P$ anterior-posterior, $B M D$ bone mineral density, $C R P$ C-reactive protein, DXA dual-energy $\mathrm{x}$-ray absorptiometry, ESR erythrocyte sedimentation rate, $m S A S S S$ modified Stoke Ankylosing Spondylitis Spine Score, NA not available, NSAID nonsteroidal anti-inflammatory drug, TNFi tumor necrosis factor inhibitor, $v B M D$ volumetric BMD

have no reference values for lateral BMD measurements for men, and since there is sparse knowledge in the literature how spinal lateral BMD changes over time in the general population, our results have to be interpreted with caution. Previous studies in the general population have shown increasing AP BMD but decreasing lateral BMD over time in older men [14, 15], whereas postmenopausal women showed an increase in both AP and lateral BMD

Table 5 Comparing percent change in BMD in patients $<50$ years without and with baseline syndesmophytes

\begin{tabular}{|c|c|c|c|}
\hline \multirow{2}{*}{$\begin{array}{l}\text { Measuring } \\
\text { site }\end{array}$} & \multicolumn{2}{|l|}{$\%$ change in BMD } & \multirow{2}{*}{$\begin{array}{l}p \text { value } \\
\text { between } \\
\text { groups }\end{array}$} \\
\hline & $\begin{array}{l}\text { No syndesmophytes } \\
(n=59)\end{array}$ & $\begin{array}{l}\text { Syndesmophytes present } \\
(n=27)\end{array}$ & \\
\hline Spine AP & $1.13 \pm 5.4^{*}$ & $6.44 \pm 9.6^{* *}$ & 0.01 \\
\hline $\begin{array}{l}\text { Spine } \\
\text { lateral }\end{array}$ & $2.12 \pm 8.0$ & $6.04 \pm 11.5^{*}$ & 0.19 \\
\hline vBMD & $1.08 \pm 7.6$ & $4.15 \pm 10.0$ & 0.31 \\
\hline Total hip & $-0.02 \pm 3.6$ & $2.84 \pm 3.7^{* *}$ & 0.001 \\
\hline $\begin{array}{l}\text { Femoral } \\
\text { neck }\end{array}$ & $-3.15 \pm 5.2^{* * *}$ & $-0.48 \pm 5.0$ & 0.04 \\
\hline $\begin{array}{l}\text { Total } \\
\text { radius }\end{array}$ & $-0.35 \pm 2.9$ & $-0.68 \pm 3.1$ & 0.80 \\
\hline
\end{tabular}

Values are presented as mean \pm SD

${ }^{*} p<0.05,{ }^{* *} p<0.01,{ }^{* * *} p<0.001$, versus baseline

Significant $p$ values are shown in bold typeface

$A P$ anterior-posterior, $B M D$ bone mineral density, $V B M D$ volumetric $B M D$
[15]. Perimenopausal women showed a decrease in AP BMD but had a statistically nonsignificant decrease in lateral BMD [32]. Nevertheless, the increase in AP and lateral BMD in this current study was significant for men. Men also had significantly higher mSASSS score than women. We were not able to show an association between osteoproliferation and increased spinal BMD, except in younger patients in the AP projection. In a study by Kaya et al., AS patients had increased AP spine BMD and SASSS over 2 years, without a correlation between the changes [10]. Wang et al. reported increased AP spine $\mathrm{BMD}$, but performed no analysis to evaluate an association between osteoproliferation and $\triangle \mathrm{BMD}$ [12]. Tan et al. recently reported improved detection of syndesmophytes by computed tomography compared to x-ray and further reported that syndesmophytes may form around the intervertebral discs [33, 34]. Thus, osteoproliferation is underestimated by mSASSS and the lateral projection of the lumbar spine DXA does not exclude all osteoproliferation. Using dual-energy quantitative computed tomography (DEQCT), Karberg et al. suggested that bone growth and bone loss occur in parallel in the spine in AS patients [35]. We suggest that it would be of great value to examine AS patients longitudinally with both DXA and QCT in order to better separate vertebral cortical and trabecular bone loss and bone proliferation. Treatment was 


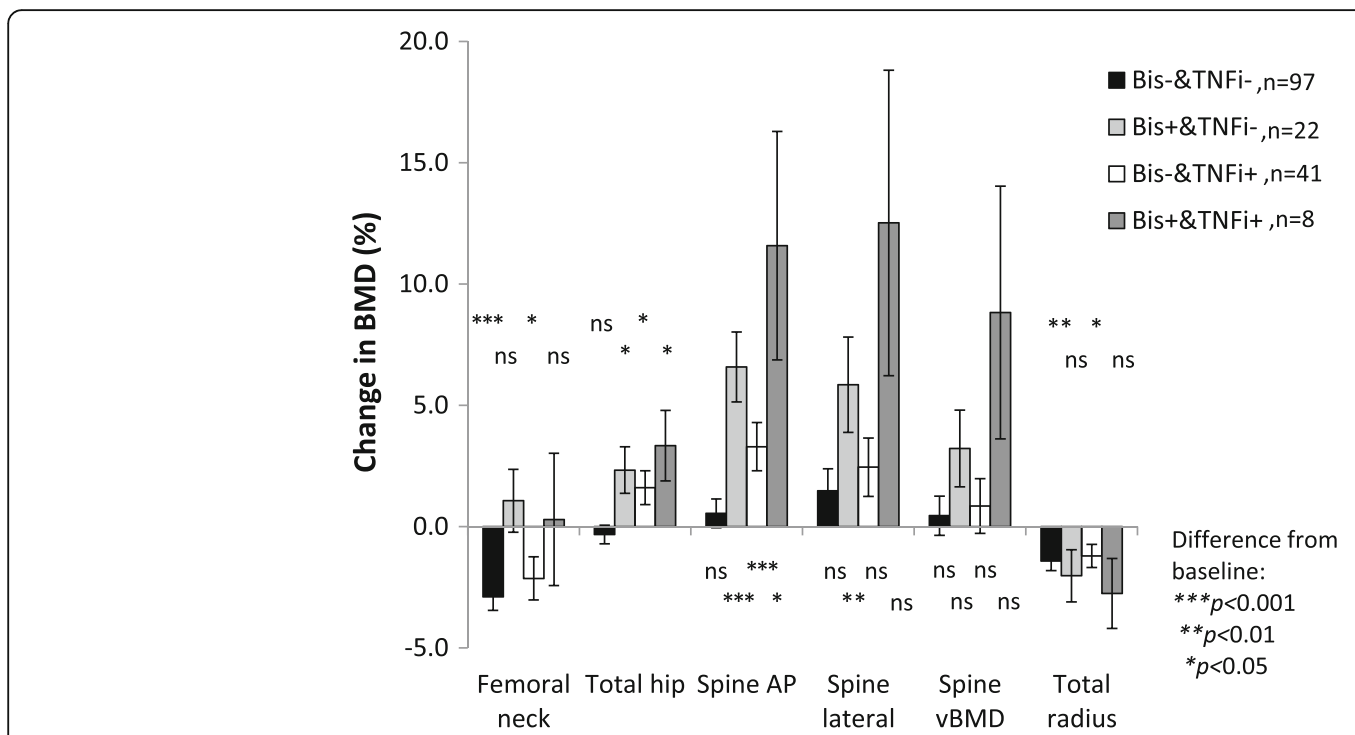

Fig. 3 Mean change (percent) in bone mineral density over 5 years according to ever exposure to medication during follow-up; patients not exposed to bisphosphonates or TNFi, patients ever exposed to bisphosphonates but not to TNFi during follow-up, patients ever exposed to TNFi but not bisphosphonates during follow up, and patients ever exposed to both TNFi and bisphosphonate during follow-up. Error bars represent SEM. AP anterior-posterior, Bis bisphosphonate, BMD bone mineral density, ns not significant, TNFi tumor necrosis factor inhibitor, VBMD volumetric BMD

also shown to have an influence on the increases in spinal BMD. Use of TNFi was a predictor for increases in AP BMD, and bisphosphonates predicted increases in both $\mathrm{AP}$ and lateral spine BMD. Patients without such treatments did not show an increase in the spinal BMD.
However, our study was not designed to study treatment effects, and the use of propensity score matching was not considered relevant due to low number of TNFi-exposed patients who also had a substantial variation in treatment duration and different starting points.

Table 6 Multiple linear regression analyses, $\triangle B M D(\%)$ as adependent variable, with no exposure to TNFi or bisphosphonates.

\begin{tabular}{|c|c|c|c|c|c|c|c|c|c|c|c|c|}
\hline \multirow[t]{2}{*}{ Constant } & \multicolumn{2}{|c|}{$\begin{array}{l}\text { Femoral neck } \\
14.0\end{array}$} & \multicolumn{2}{|c|}{$\begin{array}{l}\text { Total hip } \\
5.53\end{array}$} & \multicolumn{2}{|c|}{$\begin{array}{l}\text { Spine AP } \\
-16.4\end{array}$} & \multicolumn{2}{|c|}{$\begin{array}{l}\text { Spine lateral } \\
-54.4\end{array}$} & \multicolumn{2}{|c|}{$\begin{array}{l}\text { Spine vBMD } \\
-47.6\end{array}$} & \multicolumn{2}{|c|}{$\begin{array}{l}\text { Total radius } \\
3.58\end{array}$} \\
\hline & $\bar{\beta}$ & $p$ & $\beta$ & $p$ & $\beta$ & $p$ & $\bar{\beta}$ & $p$ & $\beta$ & $p$ & $\beta$ & $p$ \\
\hline \multicolumn{13}{|l|}{ Baseline } \\
\hline BMD at same site, $\mathrm{g} / \mathrm{cm}^{2}$ & 0.09 & 1.0 & 4.90 & 0.1 & 3.20 & 0.4 & -6.94 & 0.3 & -47.9 & 0.06 & 9.73 & 0.2 \\
\hline Age, years & -0.08 & 0.1 & -0.02 & 0.6 & 0.03 & 0.6 & 0.03 & 0.7 & -0.05 & 0.5 & -0.11 & 0.005 \\
\hline Sex & -0.53 & 0.7 & -0.75 & 0.4 & -2.11 & 0.1 & -1.42 & 0.5 & -0.40 & 0.8 & 0.15 & 0.9 \\
\hline Pack years & 0.17 & 0.01 & 0.07 & 0.08 & 0.12 & 0.07 & 0.20 & 0.04 & 0.16 & 0.07 & -0.09 & 0.03 \\
\hline mSASSS, score & 0.08 & 0.06 & 0.01 & 0.7 & -0.07 & 0.1 & -0.07 & 0.3 & -0.03 & 0.6 & 0.02 & 0.5 \\
\hline \multicolumn{13}{|l|}{ During follow-up } \\
\hline Time between DXA, months & -0.27 & 0.4 & -0.16 & 0.4 & 0.21 & 0.5 & 1.00 & 0.02 & 1.00 & 0.006 & -0.09 & 0.6 \\
\hline$\Delta$ weight, $\mathrm{kg}$ & 0.05 & 0.7 & 0.25 & 0.001 & 0.38 & 0.001 & 0.60 & 0.001 & 0.61 & 0.001 & 0.04 & 0.5 \\
\hline NSAID-index, 0-100 & 0.01 & 0.3 & 0.01 & 0.4 & 0.03 & 0.08 & 0.03 & 0.2 & 0.021 & 0.3 & 0.01 & 0.2 \\
\hline Mean ESR last 5 years, $\mathrm{mm} / \mathrm{h}$ & -0.19 & 0.01 & -0.11 & 0.02 & -0.09 & 0.3 & -0.24 & 0.04 & -0.21 & 0.04 & NA & \\
\hline Mean CRP last 5 years, mg/L & NA & & NA & & NA & & NA & & NA & & -0.14 & 0.06 \\
\hline$R^{2}$ & 0.21 & & 0.32 & & 0.27 & & 0.28 & & 0.34 & & 0.29 & \\
\hline
\end{tabular}

Betas are unstandardized coefficients

Coding for sex: $0=\operatorname{man}, 1=$ woman

Number of patients $=97$

Significant $p$ values are shown in bold typeface

$A P$ anterior-posterior, $B M D$ bone mineral density, $C R P$ C-reactive protein, $D X A$ dual-energy x-ray absorptiometry, ESR erythrocyte sedimentation rate, $m S A S S S$ modified Stoke Ankylosing Spondylitis Spine Score, NA not available, NSAID nonsteroidal anti-inflammatory drug, TNFi tumor necrosis factor inhibitor, vBMD volumetric BMD 
In the multiple linear regression analyses we found increased weight during follow-up to be associated with increased BMD at the total hip and spine. Both lean and fat mass are known determinants of bone mass and have a positive effect on BMD [36]. On the other hand, fat can also cause bias in the measurements and overestimate BMD [37]. Irrespective of mechanism, the estimates for the other predictors are likely to be valid since change in weight was adjusted for in the multiple linear regression analyses.

Exposure to bisphosphonates was shown to have a positive impact on BMD in the spine, the total hip and, to a certain extent, at the femoral neck. In a retrospective study on AS patients grouped according to treatment agents, no differences between the treatment groups were found for $\triangle B M D$ except for increased trochanteric BMD if the patients had received both bisphosphonates and TNFi [27]. A randomized placebo-controlled trial on the effect of alendronic acid on BMD in nonosteoporotic AS patients found no difference in $\triangle B M D$ in the two groups after 1 year [38]. TNFi therapy has been shown to improve lumbar spine and total hip BMD in some longitudinal studies in line with our findings [39]. Concerning NSAIDs, we found no significant effect on BMD related to NSAIDs. Results on the effect of NSAIDs on BMD in the general population in observational studies are conflicting [40-42]. The subject is sparsely studied in spondyloarthritis. One recent longitudinal study reported a protective effect of NSAID use on hip BMD in patients with early inflammatory back pain [43], but the result needs to be confirmed.

The clinical concern with low BMD is the risk for fractures. Previous studies on patients with AS have shown associations with low BMD at the spine and hip region and with prevalent VF [44-46]. In one of these studies new or worsening of VF was associated with both lower lumbar spine and hip BMD at baseline [45]. The association of BMD loss over time and development of VF has not been investigated in AS patients, and in this current study it is not possible to elucidate the clinical implications of the bone loss observed at the femoral neck.

One limitation with our study is the lack of a control group for BMD measurements. However, the current study, with a wide age range, would have needed a large control group. The large age- and sexmatched reference material in the DXA scanner was deemed sufficient. Also, using Z-scores, results from other studies can be compared to the current results. Another limitation is the lack of a reference material for the lateral projection for men.

Strengths of this study are the long follow-up time and the large and well characterized patient group with many factors, potentially able to affect BMD, identified and analyzed.

\section{Conclusion}

After 5 years BMD decreased at the femoral neck and the total radius and increased at the lumbar spine in AS patients, both in the AP and the lateral projections. The increases in the lateral projection, as well as in the AP projection, might be influenced by osteoproliferation and we suggest that the best site to assess bone loss in AS patients is the femoral neck. This study also indicates that inflammation has an adverse effect and that bisphosphonates and TNFi have a positive impact on BMD in AS patients.

\section{Abbreviations}

AP: Anterior-posterior; AS: Ankylosing spondylitis; ASAS: Assessment of SpondyloArthritis International Society; ASDAS-CRP: Ankylosing Spondylitis Disease Activity Score based on C-reactive protein; BASDAl: Bath Ankylosing Spondylitis Disease Activity Index; BASFl: Bath Ankylosing Spondylitis Functional Index; BAS-G: Bath Ankylosing Spondylitis Patient Global Score; BASMI: Bath Ankylosing Spondylitis Metrology Index; BMD: Bone mineral density; CRP: C-reactive protein; CV: Coefficient of variation; DEQCT: Dualenergy quantitative computed tomography; DXA: Dual-energy $x$-ray absorptiometry; ESR: Erythrocyte sedimentation rate; mSASSS: Modified Stoke Ankylosing Spondylitis Spinal Score; NSAID: Nonsteroidal anti-inflammatory drug; SASSS: Stoke Ankylosing Spondylitis Spine Score; SD: Standard deviation; SEM: Standard error of the mean; TNFi: Tumor necrosis factor inhibitors; VBMD: Volumetric bone mineral density; VF: Vertebral fracture; WHO: World Health Organization

\section{Acknowledgements}

We wish to thank all the patients who participated in the study. We are grateful to the research nurses Vera Börjesson and Kerstin Larsson at Sahlgrenska University Hospital for their assistance with the patients, and to Ulrika Hjertonsson, Vera Gligoric, and Marie-Louise Lindquist at the Osteoporosis Clinic for the DXA measurements. We also want to thank Tony Jurkiewich and Berit Kluft at the radiology department for help with the radiographs.

\section{Funding}

This study was supported by grants from the Health and Medical Care Executive Board of the Västra Götaland, Rune and Ulla Amlövs foundation for Rheumatology Research, Göteborg's Association Against Rheumatism, The Swedish Association Against Rheumatism, The Swedish Society of Medicine, The Medical Society of Göteborg, the Region Västra Götaland (agreement concerning research and education of doctors), Controlling Chronic Inflammatory Diseases with Combined Efforts (COMBINE), and the Margareta Rheuma research foundation.

\section{Availability of data and materials}

The datasets generated and/or analyzed during the current study are not publicly available due to Swedish legislation (the Personal Data Act), but a limited and fully anonymized dataset containing the individual patient data that support the main analyses is available from the corresponding author on request.

\section{Authors' contributions}

$\mathrm{AD}$ contributed to the acquisition, analysis, and interpretation of data, and drafting the manuscript. EK contributed to the design of the study and acquisition, analysis, and interpretation of data. ML, MG, and JG contributed to the acquisition and interpretation of data. $\mathrm{MH}$ and ER contributed to the acquisition of data. $\mathrm{HC}$ contributed to the conception and design of the work. LTJ contributed to the drafting of the manuscript and interpretation of data. HFdE contributed to the conception and design of the work,

acquisition, analysis, and interpretation of data, and drafting the manuscript. All authors critically reviewed the manuscript and approved the final version to be published. 


\section{Ethics approval and consent to participate}

The study was approved by the Regional Ethics Committee in Gothenburg, Sweden (reference number Dnr: 690-13) and was performed in accordance with the Helsinki declaration. Written informed consent was obtained.

\section{Consent for publication}

Not applicable.

\section{Competing interests}

ML has received lecturing fees from Amgen, Meda, Renapharma, and Lilly, and consulting fees from Radius Health. MG has received Advisory Board Fees and lecturing fees from Novartis. LTJ has received Advisory Board Fees from Novartis, Celgene, and MSD. HFdE has received Advisory Board Fees from Sandoz and Novartis, and an unrestricted grant from Novartis. The remaining authors declare that they have no competing interests.

\section{Publisher's Note}

Springer Nature remains neutral with regard to jurisdictional claims in published maps and institutional affiliations.

\section{Author details}

'Department of Rheumatology and Inflammation Research, Sahlgrenska Academy at University of Gothenburg, Box 480, 40530 Gothenburg, Sweden. ${ }^{2}$ Geriatric Medicine, Institute of Medicine, Sahlgrenska Academy at University of Gothenburg and Sahlgrenska University Hospital, 41345 Gothenburg, Sweden. ${ }^{3}$ Department of Radiology, Faculty of Medicine and Health, Örebro University, 70182 Örebro, Sweden. ${ }^{4}$ Department of Clinical Sciences, Lund University, Box 117, 22100 Lund, Sweden. ${ }^{5}$ Department of Radiology, Sahlgrenska University Hospital/Mölndal, 43180 Mölndal, Sweden. ${ }^{6}$ Section of Rheumatology, Södra Älvsborg Hospital, 50182 Borås, Sweden. ${ }^{7}$ Section of Rheumatology, Alingsås Hospital, 44133 Alingsås, Sweden. ${ }^{8}$ Department of Public Health and Clinical Medicine, Rheumatology, Umeå University, 90187 Umeå, Sweden.

\section{Received: 30 March 2017 Accepted: 20 November 2017} Published online: 08 December 2017

\section{References}

1. Donnelly S, Doyle DV, Denton A, Rolfe I, McCloskey EV, Spector TD. Bone mineral density and vertebral compression fracture rates in ankylosing spondylitis. Ann Rheum Dis. 1994;53(2):117-21.

2. Mitra D, Elvins DM, Speden DJ, Collins AJ. The prevalence of vertebral fractures in mild ankylosing spondylitis and their relationship to bone mineral density. Rheumatology (Oxford). 2000;39(1):85-9.

3. Will R, Palmer R, Bhalla AK, Ring F, Calin A. Osteoporosis in early ankylosing spondylitis: a primary pathological event? Lancet. 1989;2(8678-8679):1483-5.

4. Briot K, Roux C. Inflammation, bone loss and fracture risk in spondyloarthritis. RMD Open. 2015;1(1):e000052. doi:10.1136/rmd-open2015-000052.

5. Cooper C, Carbone L, Michet C, Atkinson E, O'Fallon W, Melton L. Fracture risk in patients with ankylosing spondylitis: a population based study. J Rheumatol. 1994;21:1877-82.

6. Kanis JA. Assessment of fracture risk and its application to screening for postmenopausal osteoporosis: synopsis of a WHO report. Osteoporos Int. 1994;4(6):368-81.

7. Lee Y, Schlotzhauer T, Ott S, van Vollenhoven R, Hunter J, Shapiro J. Skeletal status of men with early and late ankylosing spondylitis. Am J Med. 1997;103:233-41.

8. Yu W, Gluer CC, Fuerst T, Grampp S, Li J, Lu Y, Genant HK. Influence of degenerative joint disease on spinal bone mineral measurements in postmenopausal women. Calcif Tissue Int. 1995;57(3):169-74.

9. Gratacos J, Collado A, Pons F, Osaba M, Sanmarti R, Roque M. Significant loss of bone mass in patients with early, active ankylosing spondylitis: a follow-up study. Arthritis Rheum. 1999;42(11):2319-24.

10. Kaya A, Ozgocmen S, Kamanli A, Ardicoglu O. Bone loss in ankylosing spondylitis: does syndesmophyte formation have an influence on bone density changes? Med Princ Pract. 2009;18(6):470-6.

11. Maillefert JF, Aho LS, El Maghraoui A, Dougados M, Roux C. Changes in bone density in patients with ankylosing spondylitis: a two-year follow-up study. Osteoporos Int. 2001;12(7):605-9.
12. Wang DM, Zeng QY, Chen SB, Gong Y, Hou ZD, Xiao ZY. Prevalence and risk factors of osteoporosis in patients with ankylosing spondylitis: a 5-year follow-up study of 504 cases. Clin Exp Rheumatol. 2015;33(4):465-70.

13. Haugeberg G, Bennett AN, McGonagle D, Emery P, Marzo-Ortega H. Bone loss in very early inflammatory back pain in undifferentiated spondyloarthropathy: a 1-year observational study. Ann Rheum Dis. 2010;69(7):1364-6.

14. Zmuda JM, Cauley JA, Glynn NW, Finkelstein JS. Posterior-anterior and lateral dual-energy x-ray absorptiometry for the assessment of vertebral osteoporosis and bone loss among older men. J Bone Miner Res. 2000; 15(7):1417-24.

15. Melton 3rd LJ, Khosla S, Atkinson EJ, O'Connor MK, O'Fallon WM, Riggs BL. Cross-sectional versus longitudinal evaluation of bone loss in men and women. Osteoporos Int. 2000;11(7):592-9.

16. van der Linden S, Valkenburg HA, Cats A. Evaluation of diagnostic criteria for ankylosing spondylitis. A proposal for modification of the New York criteria. Arthritis Rheum. 1984;27(4):361-8.

17. Calin A, Garrett S, Whitelock H, Kennedy LG, O'Hea J, Mallorie P, Jenkinson T. A new approach to defining functional ability in ankylosing spondylitis: the development of the Bath Ankylosing Spondylitis Functional Index. J Rheumatol. 1994;21(12):2281-5.

18. Garrett S, Jenkinson T, Kennedy LG, Whitelock H, Gaisford P, Calin A. A new approach to defining disease status in ankylosing spondylitis: the Bath Ankylosing Spondylitis Disease Activity Index. J Rheumatol. 1994; 21(12):2286-91.

19. Jenkinson TR, Mallorie PA, Whitelock HC, Kennedy LG, Garrett SL, Calin A. Defining spinal mobility in ankylosing spondylitis (AS). The Bath AS Metrology Index. J Rheumatol. 1994;21(9):1694-8.

20. Jones SD, Steiner A, Garrett SL, Calin A. The Bath Ankylosing Spondylitis Patient Global Score (BAS-G). Br J Rheumatol. 1996;35(1):66-71.

21. Lukas C, Landewe R, Sieper J, Dougados M, Davis J, Braun J, van der Linden $S$, van der Heijde D. Development of an ASAS-endorsed disease activity score (ASDAS) in patients with ankylosing spondylitis. Ann Rheum Dis. 2009; 68(1):18-24.

22. van der Heijde D, Lie E, Kvien TK, Sieper J, Van den Bosch F, Listing J, Braun J, Landewe R. ASDAS, a highly discriminatory ASAS-endorsed disease activity score in patients with ankylosing spondylitis. Ann Rheum Dis. 2009; 68(12):1811-8.

23. Dougados M, Simon P, Braun J, Burgos-Vargas R, Maksymowych WP, Sieper J, van der Heijde D. ASAS recommendations for collecting, analysing and reporting NSAID intake in clinical trials/epidemiological studies in axial spondyloarthritis. Ann Rheum Dis. 2011;70(2):249-51.

24. Gordon CM, Leonard MB, Zemel BS. 2013 Pediatric Position Development Conference: executive summary and reflections. J Clin Densitom. 2014;17(2):219-24.

25. Creemers MC, Franssen MJ, van't Hof MA, Gribnau FW, van de Putte LB, van Riel PL. Assessment of outcome in ankylosing spondylitis: an extended radiographic scoring system. Ann Rheum Dis. 2005;64(1):127-9.

26. Genant $H$, Wu C, van Kuijk C, Nevitt M. Vertebral fracture assessment using a semiquantitative technique. J Bone Miner Res. 1993;8:1137-48.

27. Kang KY, Lee KY, Kwok S-K, Ju JH, Park K-S, Hong YS, Kim H-Y, Park S-H. The change of bone mineral density according to treatment agents in patients with ankylosing spondylitis. Joint Bone Spine. 2011;78(2):188-93.

28. Bone HG, Hosking D, Devogelaer JP, Tucci JR, Emkey RD, Tonino RP, Rodriguez-Portales JA, Downs RW, Gupta J, Santora AC, et al. Ten years' experience with alendronate for osteoporosis in postmenopausal women. N Engl J Med. 2004;350(12):1189-99.

29. Gilgil E, Kacar C, Tuncer T, Butun B. The association of syndesmophytes with vertebral bone mineral density in patients with ankylosing spondylitis. J Rheumatol. 2005;32(2):292-4.

30. Ulu MA, Cevik R, Dilek B. Comparison of PA spine, lateral spine, and femoral BMD measurements to determine bone loss in ankylosing spondylitis. Rheumatol Int. 2013;33(7):1705-11.

31. Klingberg E, Lorentzon M, Mellstrom D, Geijer M, Gothlin J, Hilme E, Hedberg M, Carlsten H, Forsblad-d'Elia H. Osteoporosis in ankylosing spondylitis - prevalence, risk factors and methods of assessment. Arthritis Res Ther. 2012;14(3):12.

32. Chapurlat RD, Garnero P, Sornay-Rendu E, Arlot ME, Claustrat B, Delmas PD. Longitudinal study of bone loss in pre- and perimenopausal women: evidence for bone loss in perimenopausal women. Osteoporos Int. 2000;11(6):493-8.

33. Tan S, Yao J, Flynn JA, Yao L, Ward MM. Quantitative measurement of syndesmophyte volume and height in ankylosing spondylitis using CT. Ann Rheum Dis. 2014;73(3):544-50. 
34. Tan S, Yao J, Flynn JA, Yao L, Ward MM. Quantitative syndesmophyte measurement in ankylosing spondylitis using $C \mathrm{C}$ : Iongitudinal validity and sensitivity to change over 2 years. Ann Rheum Dis. 2015;74(2):437-43.

35. Karberg K, Zochling J, Sieper J, Felsenberg D, Braun J. Bone loss is detected more frequently in patients with ankylosing spondylitis with syndesmophytes. J Rheumatol. 2005;32(7):1290-8.

36. Shapses SA, Sukumar D. Bone me in obesity and weight loss. Annu Rev Nutr. 2012;32:287-309.

37. Rajamanohara R, Robinson J, Rymer J, Patel R, Fogelman I, Blake GM. The effect of weight and weight change on the long-term precision of spine and hip DXA measurements. Osteoporos Int. 2011;22(5):1503-12.

38. Khabbazi A, Noshad H, Gafarzadeh S, Hajialiloo M, Kolahi S. Alendronate effect on the prevention of bone loss in early stages of ankylosing spondylitis: a randomized, double-blind, placebo-controlled pilot study. Iran Red Crescent Med J. 2014;16(6):e18022.

39. Haroon NN, Sriganthan J, Al Ghanim N, Inman RD, Cheung AM. Effect of TNF-alpha inhibitor treatment on bone mineral density in patients with ankylosing spondylitis: a systematic review and meta-analysis. Semin Arthritis Rheum. 2014;44(2):155-61.

40. Bauer DC, Orwoll ES, Fox KM, Vogt TM, Lane NE, Hochberg MC, Stone K, Nevitt MC. Aspirin and NSAID use in older women: effect on bone mineral density and fracture risk. Study of Osteoporotic Fractures Research Group. J Bone Miner Res. 1996;11(1):29-35.

41. Morton DJ, Barrett-Connor EL, Schneider DL. Nonsteroidal anti-inflammatory drugs and bone mineral density in older women: the Rancho Bernardo study. J Bone Miner Res. 1998;13(12):1924-31.

42. Vestergaard $P$, Hermann $P$, Jensen JE, Eiken P, Mosekilde L. Effects of paracetamol, non-steroidal anti-inflammatory drugs, acetylsalicylic acid, and opioids on bone mineral density and risk of fracture: results of the Danish Osteoporosis Prevention Study (DOPS). Osteoporos Int. 2012;23(4):1255-65.

43. Briot K, Etcheto A, Miceli-Richard C, Dougados M, Roux C. Bone loss in patients with early inflammatory back pain suggestive of spondyloarthritis: results from the prospective DESIR cohort. Rheumatology (Oxford). 2016; 55(2):335-42.

44. Klingberg E, Geijer M, Gothln J, Mellstrom D, Lorentzon M, Hilme E, Hedberg $M$, Carlsten H, Forsblad-D'elia H. Vertebral fractures in ankylosing spondylitis are associated with lower bone mineral density in both central and peripheral skeleton. J Rheumatol. 2012;39(10):1987-95.

45. Maas F, Spoorenberg A, van der Slik BPG, van der Veer E, Brouwer E, Bootsma H, Bos R, Wink FR, Arends S. Clinical risk factors for the presence and development of vertebral fractures in patients with ankylosing spondylitis. Arthritis Care Res (Hoboken). 2017;69(5):694-702.

46. Geusens P, De Winter L, Quaden D, Vanhoof J, Vosse D, van den Bergh J, Somers $\mathrm{V}$. The prevalence of vertebral fractures in spondyloarthritis: relation to disease characteristics, bone mineral density, syndesmophytes and history of back pain and trauma. Arthritis Res Ther. 2015;17(1):294.

\section{Submit your next manuscript to BioMed Central and we will help you at every step:}

- We accept pre-submission inquiries

- Our selector tool helps you to find the most relevant journal

- We provide round the clock customer support

- Convenient online submission

- Thorough peer review

- Inclusion in PubMed and all major indexing services

- Maximum visibility for your research

Submit your manuscript at www.biomedcentral.com/submit

) Biomed Central 